\title{
How do Torontonians hear ethnic identity?
}

\author{
Naomi Nagy ${ }^{l}$, Michol F. Hoffman ${ }^{2}$, and James A. Walker ${ }^{3}$ \\ ${ }^{1}$ University of Toronto, ${ }^{2}$ York University, ${ }^{3}$ La Trobe \\ University
}

\begin{abstract}
More attention is being paid to the sociolinguistic consequences of urban ethnolinguistic diversity, but the origins and social meanings of ethnolects are not well understood and their role in marking ethnic identity untested. Anecdotal remarks and media attention point to Canadians' awareness of ethnically marked ways of speaking English but despite public interest, sparse research exists on perceptions of different ways of speaking. We report the results of a pilot project addressing perceptions of ethnically-marked ways of speaking English in Toronto, Canada's largest and most ethnically diverse city. To test Torontonians' ability to identify native speakers of Toronto English from different ethnic groups, we ask $\sim 100$ participants to listen to speech excerpts produced by 18 Torontonians from five of the largest ethnic groups in the city (British/Irish, Chinese, Italian, Portuguese and Punjabi). Participants were asked to identify the speakers' ethnic backgrounds, indicate how well they think the person speaks English, and whether they believe them to be from Toronto. Results confirm that Torontonians are aware of ethnically marked ways of speaking and are better able to identify speakers who affiliate more strongly with their ethnicities. Judgments of speaking English well are tied more closely to perceived than actual ethnicity.
\end{abstract}

\section{Introduction}

\subsection{Perceptions of ethnicity - what do we know?}

It is well known that "all intergroup relations are, psychologically, characterised by stereotypes (beliefs), prejudices (feelings) and discrimination (behaviour)" (Bourhis and Maass 2005: 1587). We explore the first of these as a means of countering the second and third, building on research showing that "a non-mainstream accent is likely to arouse in the hearer a perception of the generalized or stereotypical characteristics that the hearer associates with that group" (Eisenchlas and Tsurutani 2011: 216). There is a robust body of research linking language attitudes to aspects of social identity such as region (e.g. Clopper, Levi and Pisoni 2004; Evans 2011; Preston 2018; Williams, Garrett and Coupland 1999), sexual orientation and gender (e.g. Levon 2014). Studies on ethnicity have tended to focus on aspects of bilingualism such as foreign accents (Kalin et al. 1980; Hosoda and Stone-Romero 2010) or attitudes toward 'multiethnolects' (e.g., Bijvoet and Fraurud 2010; Kircher and Fox 2019a, 2019b) and varieties associated with established ethnic groups (e.g., Purnell et al. 1999). Research on perceptions of specific ethnolinguistic ancestry of native English speakers is less explored. Such variation is relevant in an ethnically and linguistically diverse English-dominant context. To the best of our knowledge, there is only one comparable study in a Canadian context (Kalin et al. 1980), but they investigated the perception of 'foreign' accents in Kingston, Ontario, at a time and in a place with far less ethnic diversity than that of Toronto today. 


\subsection{Historical context}

Toronto, Canada's largest city, is an ideal locale for studying questions about ethnolinguistic variation in English. About 50\% of its 5.5 million inhabitants (as of 2016) were born outside of Canada, and the same proportion report a language other than English or French as their mother tongue (Statistics Canada 2016). Established as York in 1793 by United Empire Loyalists fleeing the American Revolution, the city (renamed Toronto in 1834) expanded with further American immigration and (after the 1812 war with the United States) large-scale immigration from the British Isles throughout the $19^{\text {th }}$ century (Levine 2014). Thus, an English variety has been spoken by speakers of British descent for over 200 years. Immigration gradually opened to include other groups from western and northern Europe, but it was not until after the Second World War and the liberalization of Canada's immigration policy in the 1960s that the ethnic and linguistic character of Toronto expanded to include non-Europeans in large numbers (Troper 2003). The development of varieties associated to groups of non-British descent thus developed some 200 years (or more) later than the variety associated with British descent.

Each of the five groups considered in this study has been characterized by different timelines of settlement. While there was an Italian presence in Toronto as far back as the 1820 s and an Italian community began to develop at turn of the $20^{\text {th }}$ century, the largest wave of immigration from Italy occurred between the 1950s and late 1970s, mainly from the southern regions of Calabria and Sicily (Harney 1998; Zucchi 1988). This period coincides with the largest wave of Portuguese immigration, with the majority coming from the Azores (Rocha-Trindade 2009; Teixeira \& Murdie 2009). The Chinese presence in Toronto dates from the late $19^{\text {th }}$ century, but the increasingly exorbitant 'head tax' on Chinese immigration and then an outright ban from 1923 to 1947 restricted the growth of the Chinese community until the 1960s. The largest waves of Chinese immigration to Toronto began in the 1980s, primarily from Hong Kong, but more recent Chinese immigration comes from Taiwan and mainland China. Immigration from South Asia was similarly affected by racial restrictions until the 1960s. The largest wave of immigration began in the 1980s and continues today (Ornstein 2006; Statistics Canada 2016).

As a result of these and other waves of immigration, Toronto is now characterized by a high degree of ethnolinguistic diversity. Figure 1 shows the largest ethnolinguistic groups in the city, other than British/Irish or 'Canadian', according to the 2016 census. Chinese, Italian, Portuguese and South Asian are among the most numerous ethnic origins, but the differences between ethnic origin, use of the associated language as a mother tongue and as a home language across these groups provide an indication that they are undergoing shift to the majority language English to different degrees. Language shift is mitigated to some extent by the tendency of these groups to settle together in recognizable neighbourhoods. Such 'ethnic enclaves' are characterized by large concentrations of people who share the same ethnic background and continue to use their heritage language. Ethnic enclaves have been argued to promote maintenance of the heritage language but also to result in ethnically marked ways of speaking, or 'ethnolects'. In fact, Torontonians commonly remark on ethnically marked ways of speaking, and 'foreign accent' is the most widely reported basis for discrimination (Statistics Canada 2003). 


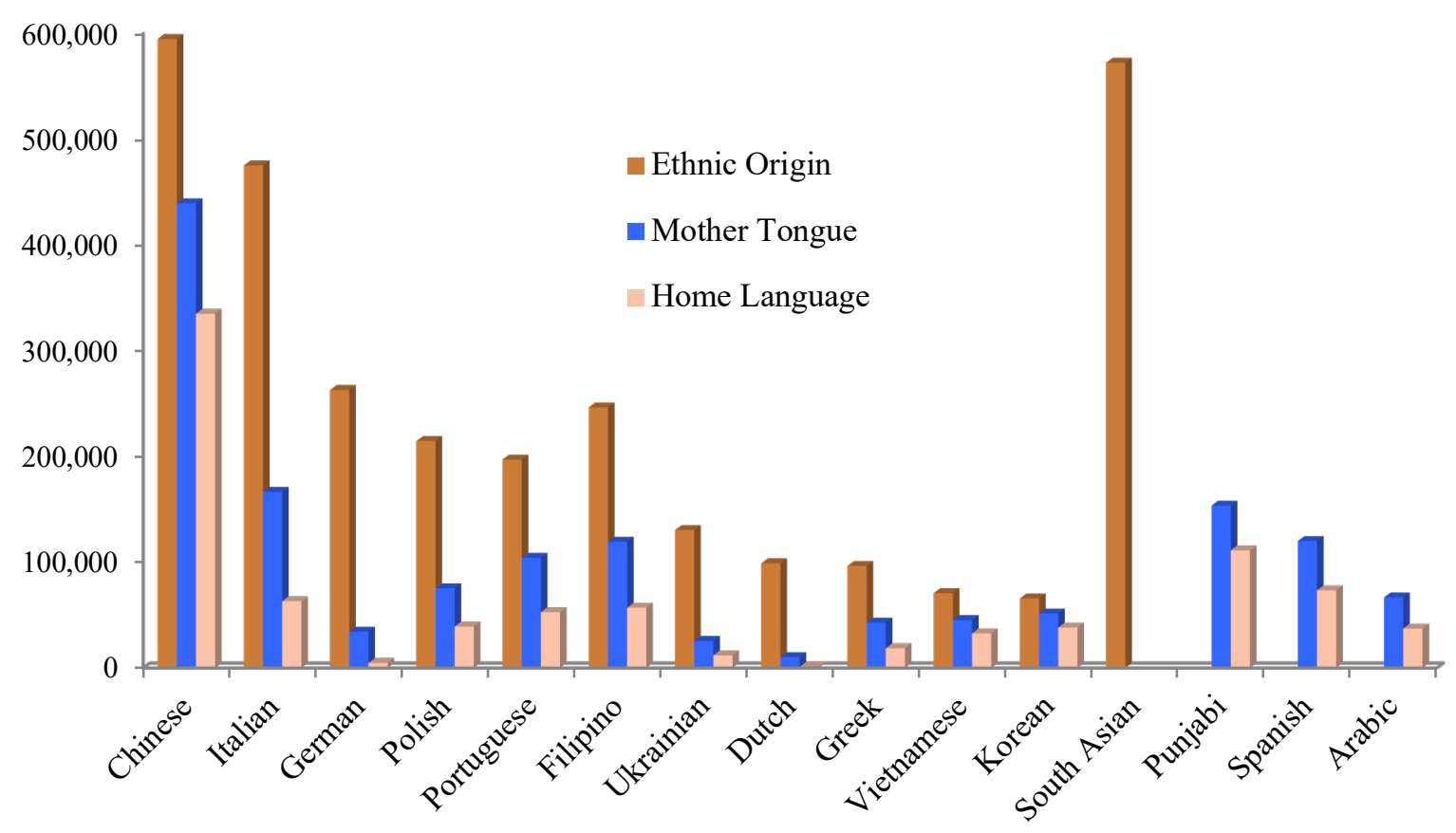

Figure 1. Number of Toronto residents claiming non-official mother tongues, home languages and ethnic origins for the largest group other than British/Irish, French and North American (Statistics Canada 2016)

\subsection{Research goals}

The goals of our larger project are to better understand the connection between linguistic behaviour and the perceptions of, and attitudes towards, different ways of speaking English in Toronto. We will ultimately investigate whether specific linguistic features or constellations of features are associated with the English of different ethnolinguistic groups in Toronto and whether Torontonians relate these features (and thus these groups of speakers) with other social attributes. In this pilot phase, which is more limited in scope, we explore whether Torontonians can (correctly) identify the ethnic background/ancestry of other English speakers from Toronto, whether some ethnic backgrounds are more identifiable and whether speakers who orient themselves more toward their ethnic backgrounds are more likely to be identified than those who orient themselves less. We are also interested in the links between ethnicity and judgments of speaking English well and being from Toronto: Are certain ethnic groups heard as speaking English "better"? Are certain ethnic groups more likely identified as "from Toronto"?

No research yet exists linking perception and production of ethnically-associated linguistic features in Toronto. To date, work has looked primarily at the extent to which speakers of different ethnic groups use certain features identified as "Canadian English" (cf. Hoffman 2010, 2017; Hoffman and Walker 2010, to appear). The experiment reported here will reveal which speakers are most easily identified and associated with particular ethnic varieties, which will allow us to examine the variation in their production and identify the features that trigger listener recognition and categorization.

We also introduce a fieldwork method using surveys loaded on iPads for flexible in-person recruitment in diverse locations and fieldworker oversight to maximize completion rates.

\section{$2 \quad$ Methods}

To address these questions, we created and deployed a questionnaire in which participants (Judges) listened to sound clips of speakers of five ethnic backgrounds (Voices): British/Irish, Chinese, Italian, Portuguese 
and Punjabi. Each group is represented by four speakers, with two strongly oriented toward their heritage ethnicity, as demonstrated by their (averaged) responses to an Ethnic Orientation (EO) Questionnaire (described in Nagy et al. [2014] and Hoffman and Walker [2010], and available online at http://projects.chass.utoronto.ca/ngn/pdf/HLVC/short questionnaire English.pdf) ("High EO"), and two oriented more toward broader Canadian culture ("Low EO"). The male and the female with the highestand lowest-scored responses to the 37 questions of the questionnaires were selected. This distribution is illustrated in Table 1. Since no EO questionnaire was administered to the British/Irish speakers, we include just one male and one female from that group.

Table 1. Social characteristics of the second-generation Toronto Voices used in the perception study

\begin{tabular}{|c|c|c|c|c|c|c|c|c|c|c|}
\hline \multirow[b]{3}{*}{ Sex: } & \multicolumn{10}{|c|}{ Ethnic Background } \\
\hline & \multicolumn{2}{|c|}{ BRITISH/IRISH } & \multicolumn{2}{|c|}{ CHINESE } & \multicolumn{2}{|c|}{ ITALIAN } & \multicolumn{2}{|c|}{ PORTUGUESE } & \multicolumn{2}{|c|}{ PUNJABI } \\
\hline & $\mathrm{F}$ & $\mathrm{M}$ & $\mathrm{F}$ & M & $\mathrm{F}$ & M & $\mathrm{F}$ & M & $\mathrm{F}$ & M \\
\hline $\mathrm{N}:$ & 1 & 1 & 2 & 2 & 2 & 2 & 2 & 2 & 2 & 2 \\
\hline Total: & 2 & & 4 & & 4 & & 4 & & 4 & \\
\hline Grand total: & 18 & & & & & & & & & \\
\hline
\end{tabular}

These clips were extracted from conversational speech in sociolinguistic interviews, conducted by members of each ethnic group, as part of the Contact in the City project (Hoffman and Walker 2010). All speakers were born and raised in Toronto and are second-generation members of one of four ethnic groups. We also include two speakers of British/Irish descent, second generation or later, who are representative of the founder population of English-speaking Toronto. We did not control for generation in this group, because no language-transfer effects are expected. Each 10-15-second clip was selected to ensure that it did not identify the speaker's background by content (i.e., they include no mention of language or community customs). (Hear sample clips at http://individual.utoronto.ca/ngn/research/TWPL soundclips.html)

Potential participants first reviewed and accepted an on-screen consent form, and had any questions answered by the research assistant presenting the survey. The 18 sound clips were presented one by one in pseudo-randomized order on an iPad tablet to Judges wearing noise-cancelling headphones, using a Qualtrics (Qualtrics, Provo, UT) on-screen survey. The survey was administered in a range of locations in order to capture a wide participant pool: homes, offices, mall food courts, university campuses, and on the street.

For each Voice, the same three questions were visible below the clip (see Figure 2). The first question asked Judges to identify "the speaker's ethnic background/ancestry" as one of the five groups included in the survey (listed alphabetically), followed by an option to select "Other" and write in an answer, as well as an "I don't know" option. The second question asked the Judge to decide if the speaker is from Toronto. The third question asked the judge how well the person speaks English. For both these questions, there were five options to allow the Judge to express their confidence in their choice. Demographic information about the participant was requested at the end of the survey: their ancestry/ethnic background, year of birth, city and country of birth, where in Toronto they currently live (by clicking on a map), how long they have lived there, and their gender identity. In this report, we examine only ethnicity, age and gender effects, with respect to the Judges.

We examine data from 103 Judges, ${ }^{1}$ distributed by age, gender and ancestry/ethnicity as shown in Figure 3. There are Judges from each of the speaker groups as well as others (African Canadian, African Caribbean, Colombian, Filipino, Japanese, Jewish, Lebanese, Gujarati, Iranian, and others who didn't specify). The average age of the Judges is 36 years and they are roughly balanced by gender.

\footnotetext{
${ }^{1} 120$ judges participated in the survey but we excluded 17 who didn't complete very many questions or were not born
} and raised in Toronto. 


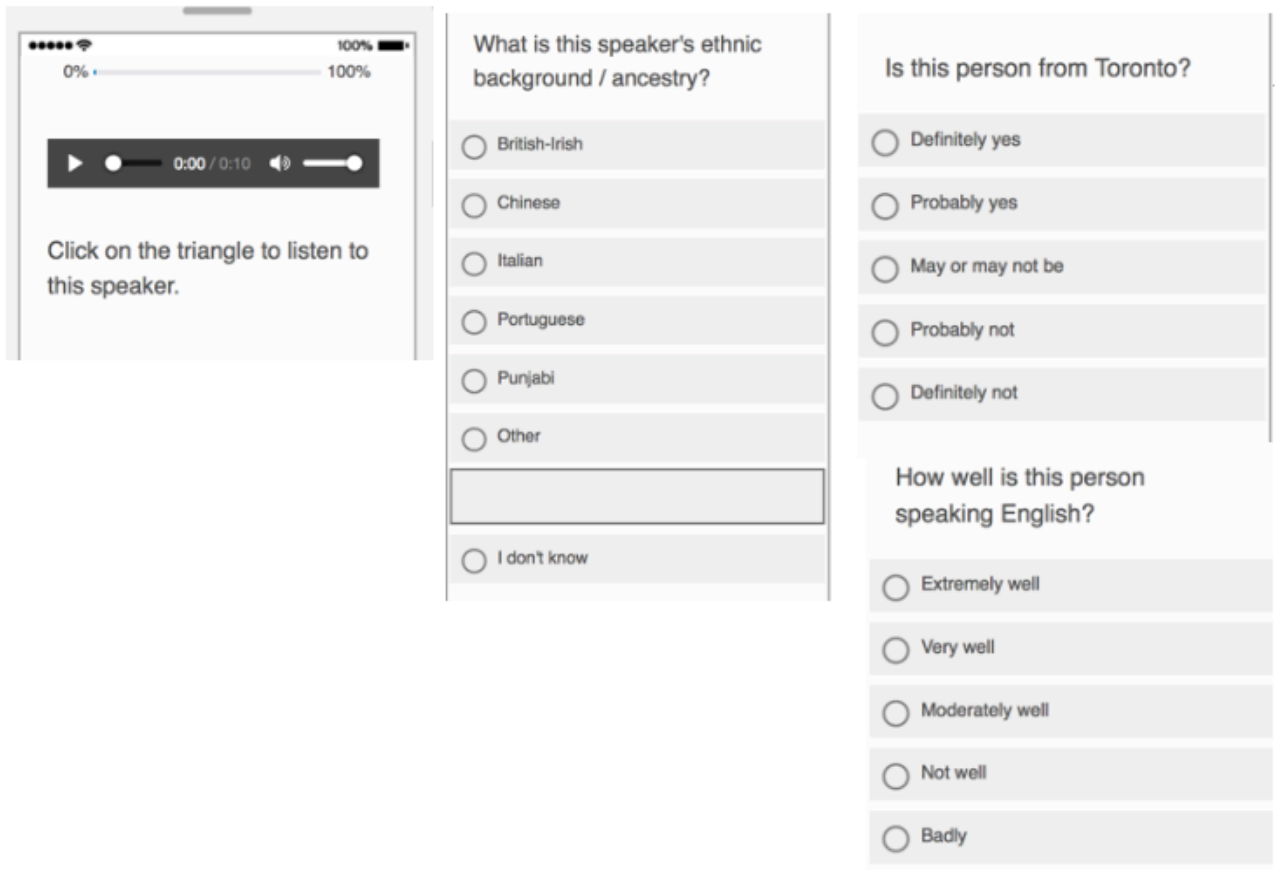

Figure 2. Presentation of questions in the survey

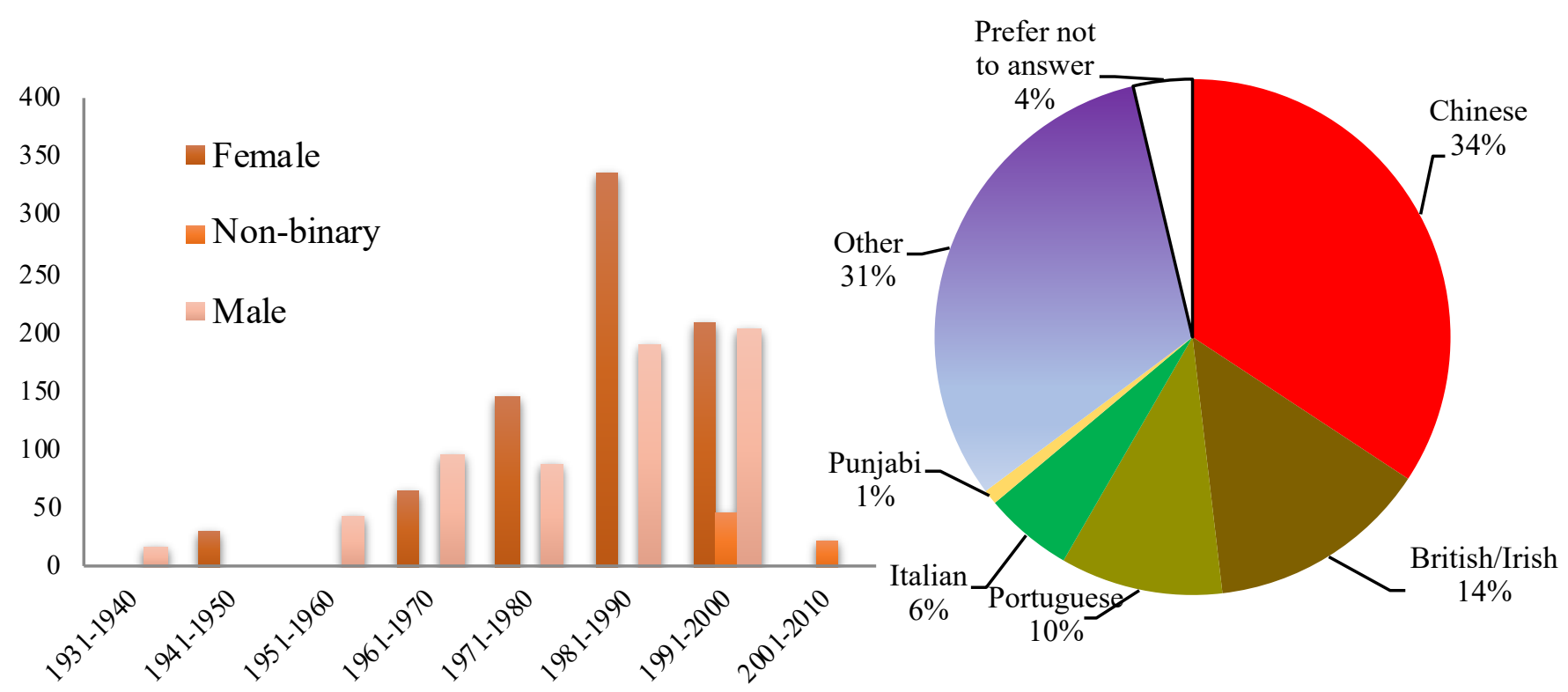

Figure 3. Distribution of responses by Judges' decade of birth, gender and ethnic background

Once the surveys were collected, responses were downloaded from Qualtrics, inspected for distributions and irregularities, and then modelled via Mixed Effects models (MEM) in Rbrul (Johnson 2009). Several models were constructed with different dependent variables: whether the judged ethnicity matched the 
actual ethnicity of the Voice, how well the Voice was judged to speak English, and how often the Voice was judged to be from Toronto. Independent variables included the judged and actual ethnicity (crossed with High vs. Low EO) of the Voice and the year of birth, gender, and ethnicity of the Judge, with Judge as a random effect to help guard against strong effects reflecting the individual views of any one participant. Best-fitting models for how accurately Voices were judged, whether Voices were judged as speaking English well and whether Voices were judged as being from Toronto appear in Appendices A-C, respectively.

Compared to many similar studies, this project differs in that Judges are not limited to university students but were recruited in a range of locations in order to include residents from across the Greater Toronto Area (see Figure 4). A second innovation is the presentation of the Voices on a tablet computer in a face-to-face format with a research assistant who was able to answer questions, clarify instructions, and ensure that the participants wore noise-cancelling headphones and completed the survey with minimal distraction. A third innovation is distinguishing, in our discussion, between actual and judged ethnicity of Voices and how these correlate with the judgments about residence and quality of spoken English (as will be discussed below). Fourth, sound clips are taken from speech produced naturalistically in an in-group context. They come from speakers for whom we have over an hour of recorded speech, already analyzed for a range of production variables, allowing future work to interrogate more closely the connections between production (discussed in Hoffman 2017; Hoffman and Walker 2010, to appear) and perception. Finally, this is the first study of this type to be conducted across a wide range of ethnic groups, in which Voices representing several ethnicities are evaluated, in a highly multiethnic city.

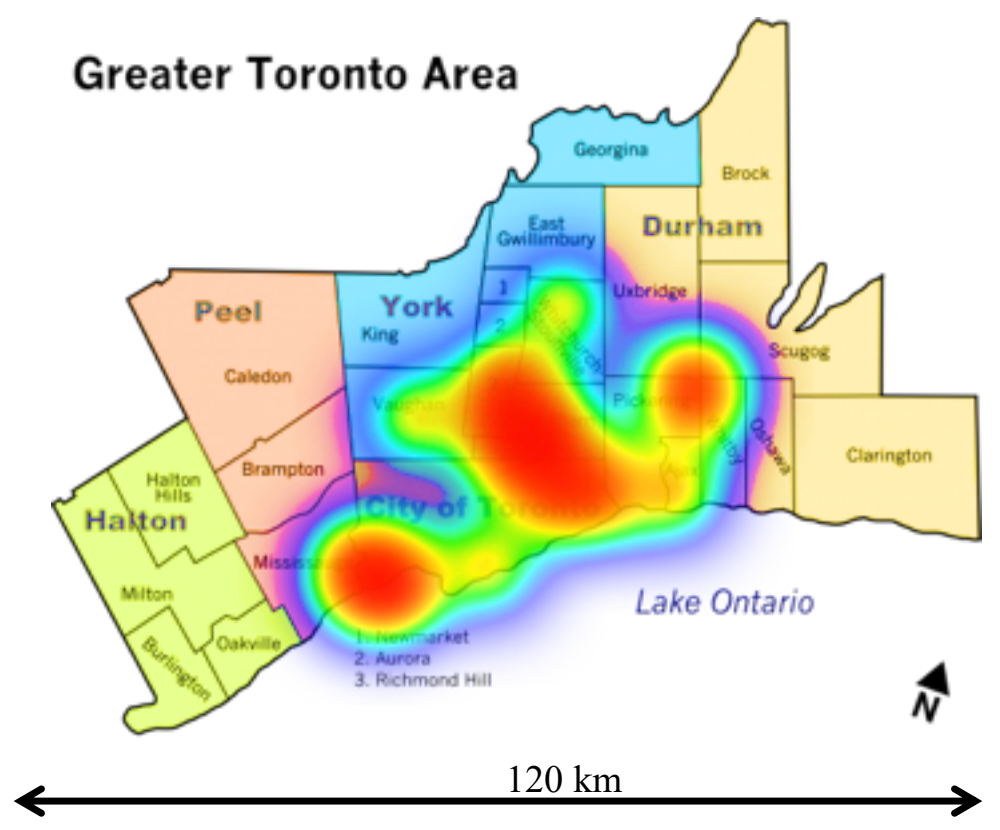

Figure 4. Distribution of Judges' residences (adapted from https://en.wikipedia.org/wiki/List_of_municipalities_in_the_Greater_Toronto_Area)

\section{$3 \quad$ Results}

In total, we examine 1,497 responses (i.e. 18 Voices x 103 Judges, excluding instances where there was no response provided). Our first observation is that these judgments are not easy: the most accurate Judges made accurate judgments of the speaker's ethnicity for about $2 / 3$ of the Voices they provided answers for, but they gave no response for (another) 1/3 of the Voices. Judges who chose the strategy of giving responses 
to all the Voices got about half of them right. The individual Judges who answered for most of the Voices ranged from $0 \%$ to $63 \%$ correct in their judgment of ethnicity.

We consider first the judgments about ethnicity, looking at some individual representative responses and then the overall trends. Of the five groups considered in this study, the Italians have maintained a presence as a community in Toronto longer than any other groups except the British/Irish. Thus, we first examine some Italian Voices, comparing the responses to two Italian male Voices, one High EO and one Low EO (see top of Figure 5; listen to sample clips at http://individual.utoronto.ca/ngn/research/TWPL soundclips.html). The Low EO Italian man was judged to be British by the majority of Judges $(63 \%)$, while his Italian ethnicity was correctly identified by only $18 \%$ of Judges. In contrast, the High EO Italian man was correctly identified as Italian $60 \%$ of the time. We see that EO makes a difference: the Low EO Italian man sounds British (to these Judges) while the High EO man sounds Italian. This difference also illustrates the wide range in how often the different Voices were correctly identified.

Compare these results with those for the most recently arrived group, Punjabi. The two pie graphs at the bottom of Figure 5 show the proportions of judgments of two Punjabi women's Voices. Once again, EO makes a difference: the Low EO Punjabi woman is correctly identified $16 \%$ of the time and the High EO Punjabi woman is correctly identified $39 \%$ of the time. We note also that these representatives of a smaller group, one newer to Toronto, are correctly identified only about half as often as the Italian men. Additionally, we see that Judges had lots of ideas about the ethnicity of these two Voices, rather than consensus.

\section{Low EO Italian Man}

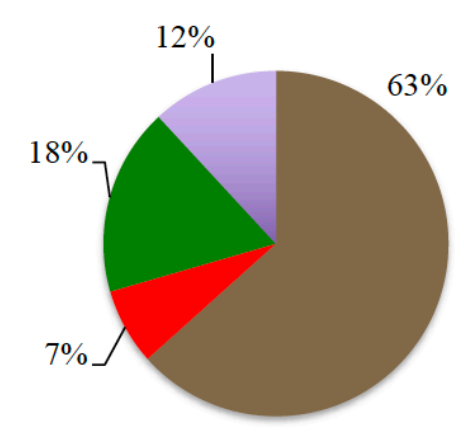

Low EO Punjabi Woman

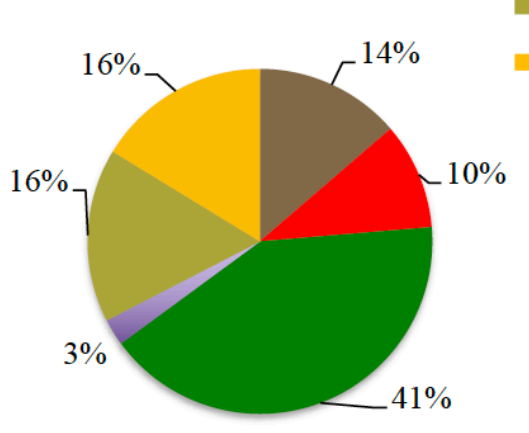

\section{High EO Italian Man}

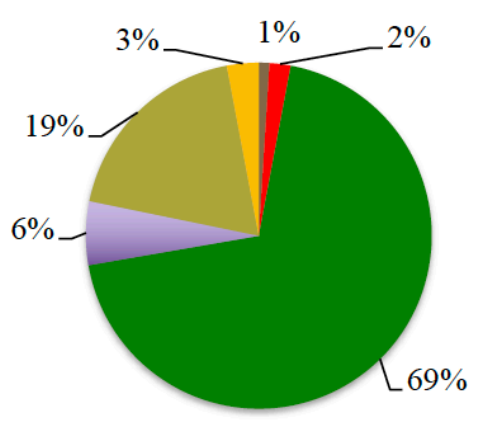

Chinese

- Italian

- Other

- Portuguese

- Punjabi

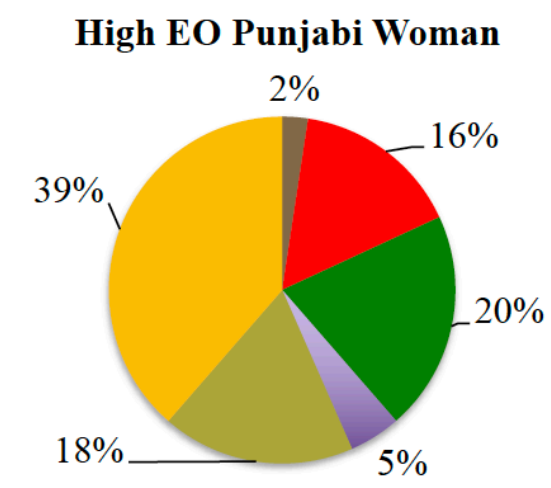

Figure 5. Ethnicity judgments of four Voices (responses to: "What is this speaker's ethnic background / ancestry?") 
Having explored a few examples, we next consider more systematically the factors that influence whether a Judge correctly identifies the ethnicity of a Voice. Recall that in the survey, the first question for each Voice asked the Judges to identify the Voice's ethnic background. As Table 2 shows, no groups are correctly identified much more than half the time. We see two clear effects. First, the larger groups (British/Irish, Italian and Chinese) are better recognized than the others. Second, EO plays a consistent role: for each ethnicity, the two High EO speakers are more often correctly identified than the two Low EO speakers, with High EO speakers identified correctly 44-57\% of the time (except Portuguese, to which we return shortly) and Low EO speakers identified correctly only $21-37 \%$ of the time. The effect of EO is bigger for the speakers representing older waves of immigration. The Portuguese are the least wellidentified, High and Low EO alike, with each of the four being identified correctly $<20 \%$ of the time. In fact, two of the four Portuguese speakers (the two males) are correctly identified $<10 \%$ of the time, that is, more than one standard deviation below average. This is not true of the other groups of Voices. Additionally, by comparing the spread of logodds for the High EO groups (2.05) to the spread for Low EO groups (1.5), we see that Judges distinguish more among the High EO groups, suggesting that there are some production differences between High EO and Low EO speakers. Further work will unravel what particular features are distinctive.

Table 2. (Partial) linear regression analysis of Judges' accuracy in identifying the ethnic background of Voices. See full analysis in Appendix A.

\begin{tabular}{lccc}
\hline Ethnicity & Logodds & $\mathrm{n}$ & Accuracy \\
\hline Italian, High EO & 0.971 & 175 & $\mathbf{5 7 \%}$ \\
British/Irish & 0.944 & 164 & $\mathbf{5 6 \%}$ \\
Chinese, High EO & 0.808 & 187 & $\mathbf{5 4 \%}$ \\
Punjabi, High EO & 0.425 & 166 & $\mathbf{4 4 \%}$ \\
Chinese, Low EO & 0.120 & 157 & $\mathbf{3 7 \%}$ \\
Punjabi, Low EO & -0.158 & 165 & $\mathbf{3 1 \%}$ \\
Italian, Low EO & -0.643 & 168 & $\mathbf{2 1 \%}$ \\
Portuguese, High EO & -1.078 & 160 & $\mathbf{1 5 \%}$ \\
Portuguese, Low EO & -1.389 & 155 & $\mathbf{1 2 \%}$ \\
\hline
\end{tabular}

Next we consider the effect of the ethnicity of the Judges themselves. As we do not have a well-balanced sample of Judges in this regard, we must regard these as preliminary results. First, the Portuguese and Italian Judges are the most accurate in identifying the Voices' ethnicity (see Figure 6). With the exception of the British group, these are the groups that have been settled in Toronto the longest. Setting aside the single Punjabi Judge, the British are the worst-performing group of Judges, disrupting any easy explanation related to length of settlement in Toronto. This result may be related to the fact that there are only two British Voices, so two "self" accents to identify, compared to four for each other group. 


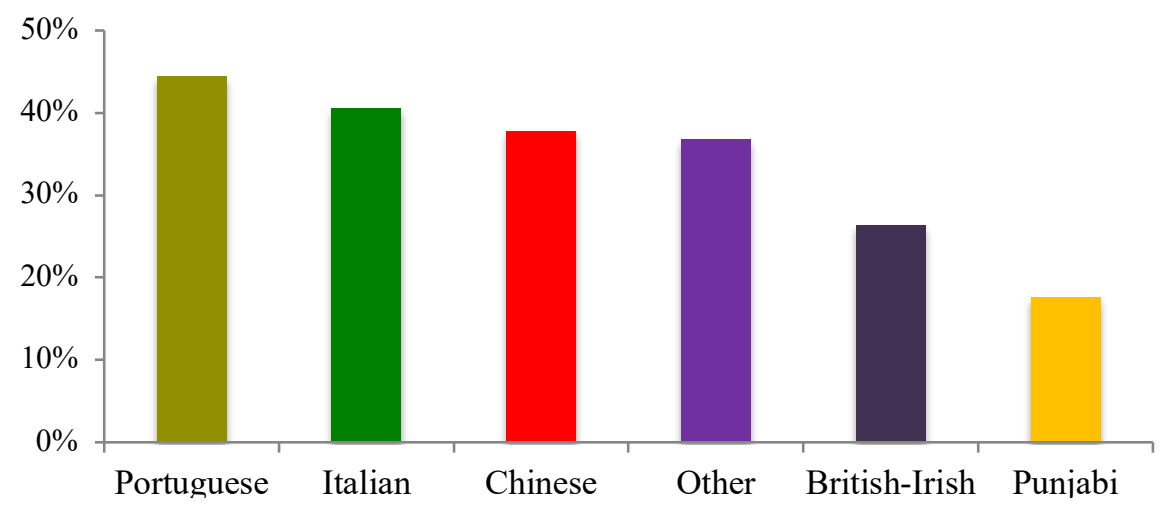

Figure 6. Accuracy of identifying ethnicity, by Judges' ethnicity

This result led us to investigate whether there was a different success rate between identifying Voices from one's own group vs. another group. We used Fisher's Exact Test to compare the success rate in identifying each Voice for Judges of the same ethnic group $v s$. Judges of all the other groups combined. For example, are British Judges, as a group, better at recognizing the British Voices than other people are?

Table 3. Self- vs. Other-judgments for British-descent Judges ( $p=1.0,2$-tailed)

\begin{tabular}{cccc}
\hline & & \multicolumn{2}{c}{ Ethnicity of VOICES } \\
& & BRITISH & NOT BRITISH \\
JUDGES & BRITISH & 14 & 8 \\
ethnicity & NOT BRITISH & 96 & 54 \\
\hline \% CORRECT IF: & & \\
Judge is same group as Voice: & $64 \%$ & \\
Judge is different from Voice: & $64 \%$ \\
\hline
\end{tabular}

In this case (see Table 3), Fisher's Exact Test indicates that there is no significant difference (Two-tailed $p=1.0$ ). We also contrasted judgments of the High EO and Low EO groups. The only significant effect from all of these comparisons is that Judges of Chinese ethnicity are significantly better at recognizing Chinese Voices than anyone else is (see Table 4), with a particular advantage for recognizing Low EO Chinese (Two-tailed $p=0.0007$ ). A possible explanation for this effect is simply that we have more Chinese Judges than any other group in this sample, except British. Overall, this finding contrasts with the finding that speakers vs. non-speakers of Multicultural London English differ in their evaluation of the variety (Kircher and Fox 2019b:1).

Table 4. Self- vs. Other-judgments for Chinese-descent Judges ( $p=0.0007,2$-tailed)

\begin{tabular}{cccc}
\hline & \multicolumn{2}{c}{ Ethnicity of VOICES } \\
& & CHINESE & Not CHINESE \\
JUDGES & CHINESE & 75 & 58 \\
ethnicity & Not CHINESE & 87 & 137 \\
\hline$\%$ CORRECT IF: & & \\
Judge is same group as Voice: & $56 \%$ \\
Judge is different from Voice: & $39 \%$ \\
\hline
\end{tabular}

Other factors considered in the first model, but which did not have significant effects, were the Voice's Gender, the Judge's Gender and Judge's Age, and whether the Voice was judged to speak well (although there is a trend that Voices judged to speak English well were slightly more often accurately identified than those judged to speak English badly), and whether the Voice was judged to be from Toronto (although 
there is a trend that Voices judged to be from Toronto were slightly more often accurately identified). We unpack the latter two trends below.

We next consider the relationship between the judgments of the Voices' ethnicity and the judgments of how well they speak English (full model in Appendix B). First, these Torontonian Judges are polite. Very few respondents judged any Voices to be speaking "badly" or "not well" (regardless of ethnicity), see Figure 7, in contrast with Kircher and Fox's (2019a:11) finding of "rather negative" attitudes toward Multicultural London English. We observe that Voices judged to be of British descent were judged to speak English "extremely well" more than all other judged ethnicities, suggesting that Judges are influenced by stereotypes of proper speech, connecting proper English to that of the founder population of Toronto and perhaps also drawing a connection to UK English.

In contrast, those Voices judged to be Portuguese had the lowest rates of judgments of speaking "extremely well" or "very well", potentially attributable to the social profile and stereotypes of these communities in Toronto. Portuguese descent youth have lower rates of high school completion and postsecondary attendance than other groups (Nunes 2004, 2008), while the British have the highest rates (see Figure 8). Thus, judgments about the English of Voices judged to be Portuguese may be biased by attitudes toward these groups (without necessarily indicating anything about the cues in these Voices). However, the Judged-as-Punjabi group is judged to speak English almost as poorly as the Judged-as-Portuguese group, while their educational attainment is quite a bit higher (again, see Figure 8).

We offer another possible explanation of the judgments of the Portuguese Voices. Hoffman and Walker (to appear) show that the Portuguese speakers in the Contact in the City corpus produce English that is phonetically quite similar to that of the British speakers for several variables. The Portuguese lead in several changes, being slightly more advanced than the British/Irish and quite far ahead of the Italian, Chinese and Punjabi speakers. One example of this can be seen in Figure 9, which shows the average formants of $/ \mathrm{u} /$ and $/ \mathrm{o} /$, two vowels that are undergoing fronting in Canadian English, for each ethnic group. Thus, Portuguese Voices may have been "mis-judged" as British because their pronunciation more closely matches the British/Irish than any other group. In contrast, Punjabi speakers lag the most behind the Anglos in production of these Canadian English changes, and they are rarely mistaken for British/Irish in this study. Thus, their speech may be judged negatively in spite of their having, as a group, a higher educational attainment than the British (see Figure 8).

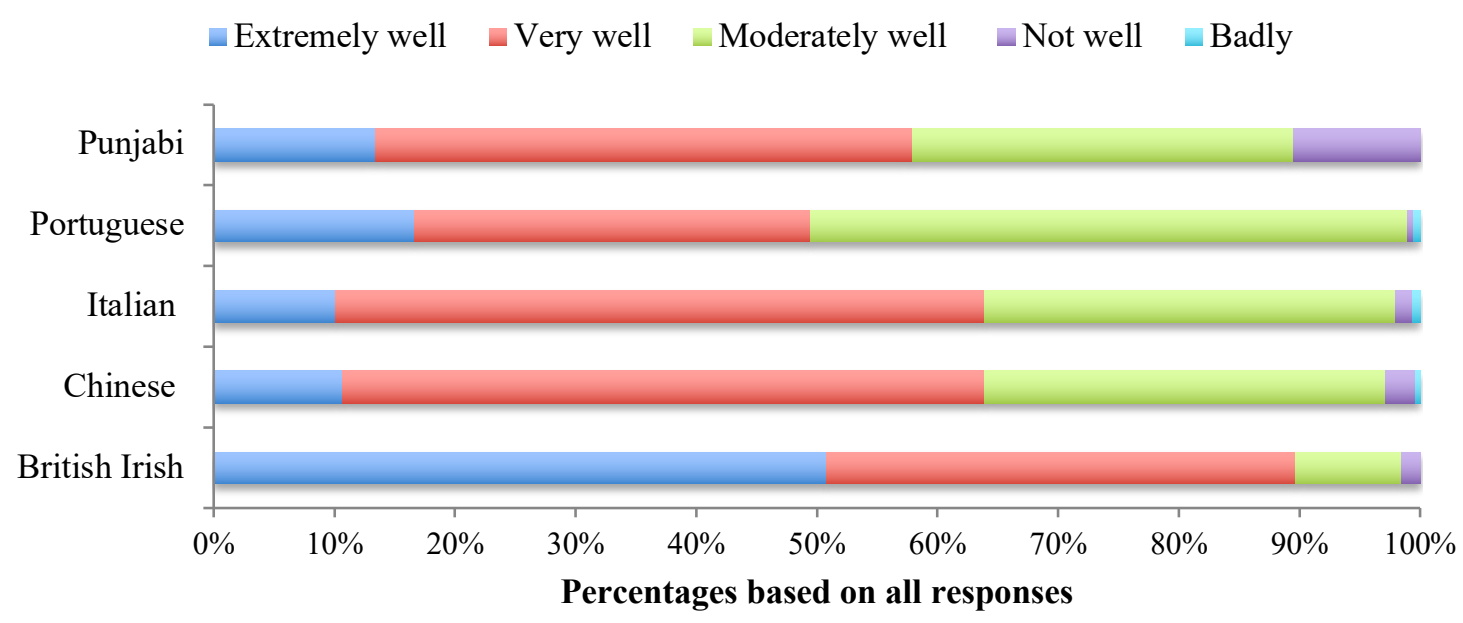

Figure 7. Judgments of how well the Voices speak, based on judged ethnicity 


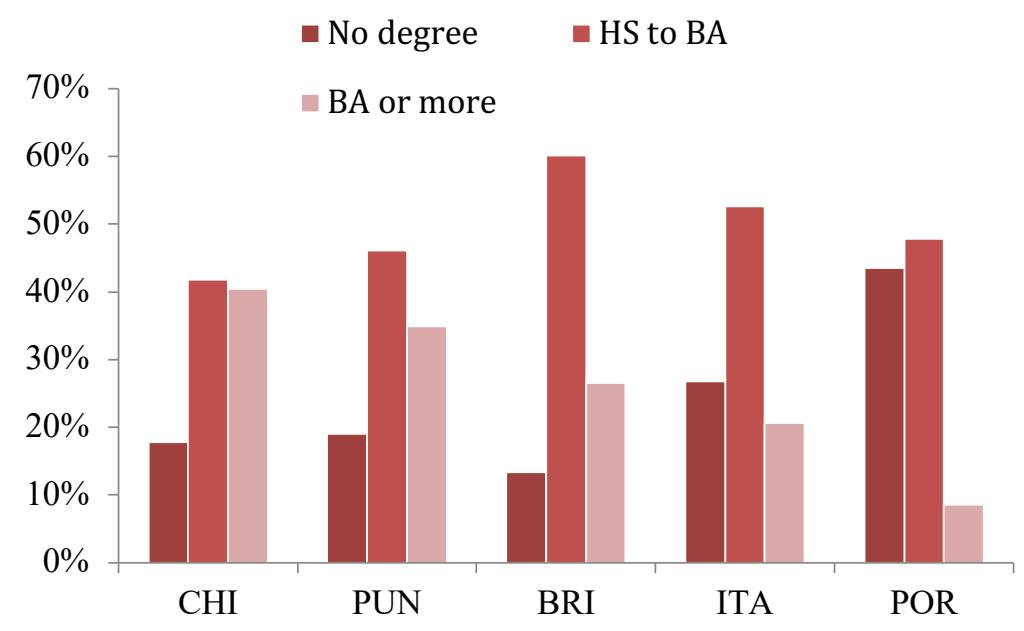

Figure 8. Educational attainment by ethnic group, Toronto Census Metropolitan Area (Statistics Canada 2016)

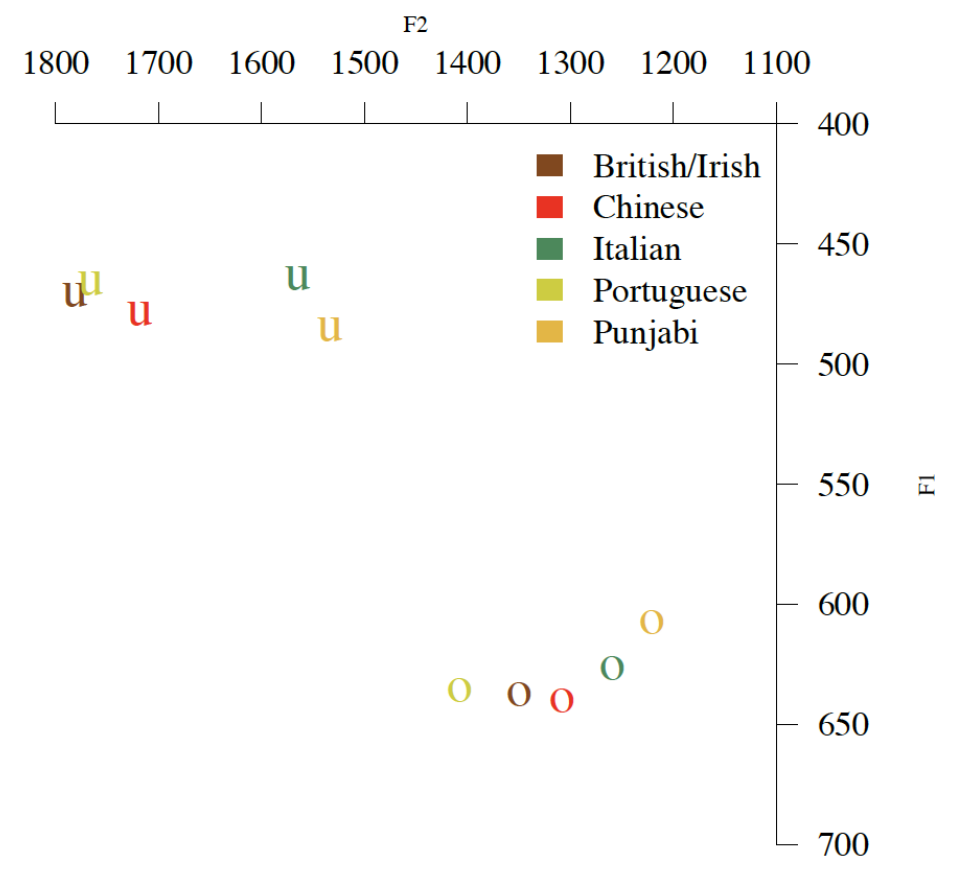

Figure 9. Fronting of /uw/ and /ow/ by ethnic group (from Hoffman 2017)

However, our most interesting finding relates to a mismatch between Judged Ethnicity, Actual Ethnicity and Judgments of Speaking English Well, illustrated in Table 5. On the left, we see a list of the judged ethnic groups ranked by factor weights from the MEM of how often they were judged to speak English "Extremely well" or "Very well." (The full model is in Appendix B.) Judged-as-British and Judged-as"Canadian" have favouring factor weights while the four more recent immigrant groups have disfavouring weights. On the right, the groups are ranked by their actual ethnicity, and the rank order by factor weight is quite different. The top five slots (corresponding to factor weights above .5) are occupied by the ethnic 
groups in the lower half on the left. The actual British/Irish-descent Voices rank below these: that is, the British/Irish are down-graded when we contrast actual to judged ethnicity, while the Italians and Chinese (High EO) are upgraded. Most importantly, judgments of speaking well are more strongly reflective of judged ethnicity than of actual ethnicity (as indicated by bigger ranges of factor weights and lower p-values). Surprisingly, the High EO Italian, Chinese and Portuguese are ranked as speaking English well. It is only in the most recently arrived group, Punjabi, that Low EO Voices are judged to speak better English than High EO Voices.

Table 5. Relationship between Judgment of Ethnicity and Judgment of Speaking English well (Ranked by factor weight)

\begin{tabular}{lcclcc}
\hline $\begin{array}{l}\text { Judged ethnicity } \\
(\boldsymbol{p}=\mathbf{6 . 5 2 e - 2 0})\end{array}$ & $\begin{array}{c}\text { Judged to speak } \\
\text { "Extremely" or } \\
\text { "Very" well }\end{array}$ & $\begin{array}{l}\text { Factor } \\
\text { weight }\end{array}$ & $\begin{array}{l}\text { Actual ethnicity } \\
(\boldsymbol{p}=\mathbf{1 . 6 9 e - 0 8 )}\end{array}$ & $\begin{array}{c}\text { Judged to speak } \\
\text { "Extremely" or } \\
\text { "Very" well }\end{array}$ & $\begin{array}{c}\text { Factor } \\
\text { weight }\end{array}$ \\
\hline Canadian & $77 \%$ & 0.84 & Italian, High EO & $71 \%$ & 0.65 \\
British-Irish & $92 \%$ & 0.84 & Chinese, High EO & $77 \%$ & 0.60 \\
\hdashline Other & $68 \%$ & 0.42 & Italian, Low EO & $77 \%$ & 0.60 \\
Italian & $65 \%$ & 0.40 & Punjabi, Low EO & $66 \%$ & 0.57 \\
Chinese & $62 \%$ & 0.34 & Portuguese, High EO & $71 \%$ & 0.54 \\
Punjabi & $49 \%$ & 0.31 & British/Irish & $77 \%$ & 0.48 \\
Portuguese & $56 \%$ & 0.27 & Portuguese, Low EO & $68 \%$ & 0.44 \\
& & & Chinese, Low EO & $54 \%$ & 0.41 \\
& & & Punjabi, High EO & $41 \%$ & 0.24 \\
\hline
\end{tabular}

We now turn to our model of the factors that influence whether a speaker is judged to be from Toronto. Chinese, British and Italian Judges (i.e., members of Toronto's three biggest ethnic groups) are most likely to judge a Voice to be from Toronto. Judgments of whether a Voice is from Toronto work similarly to judgments of speaking English well: the strongest effect is that if a Judge thinks a Voice speaks well, then they are likely to judge the Voice being from Toronto. In Figure 10 we see that people judged to be British are most likely to be judged as from Toronto, while those who are judged to be Punjabi are less likely to be judged to be from Toronto. ${ }^{2}$ The full model is in Appendix C.

\footnotetext{
${ }^{2}$ We acknowledge the potential response bias that exists because the "correct" answer is always "from Toronto." However, this bias should not affect our analysis, which compares relative rather than absolute rates of judgments for each group.
} 


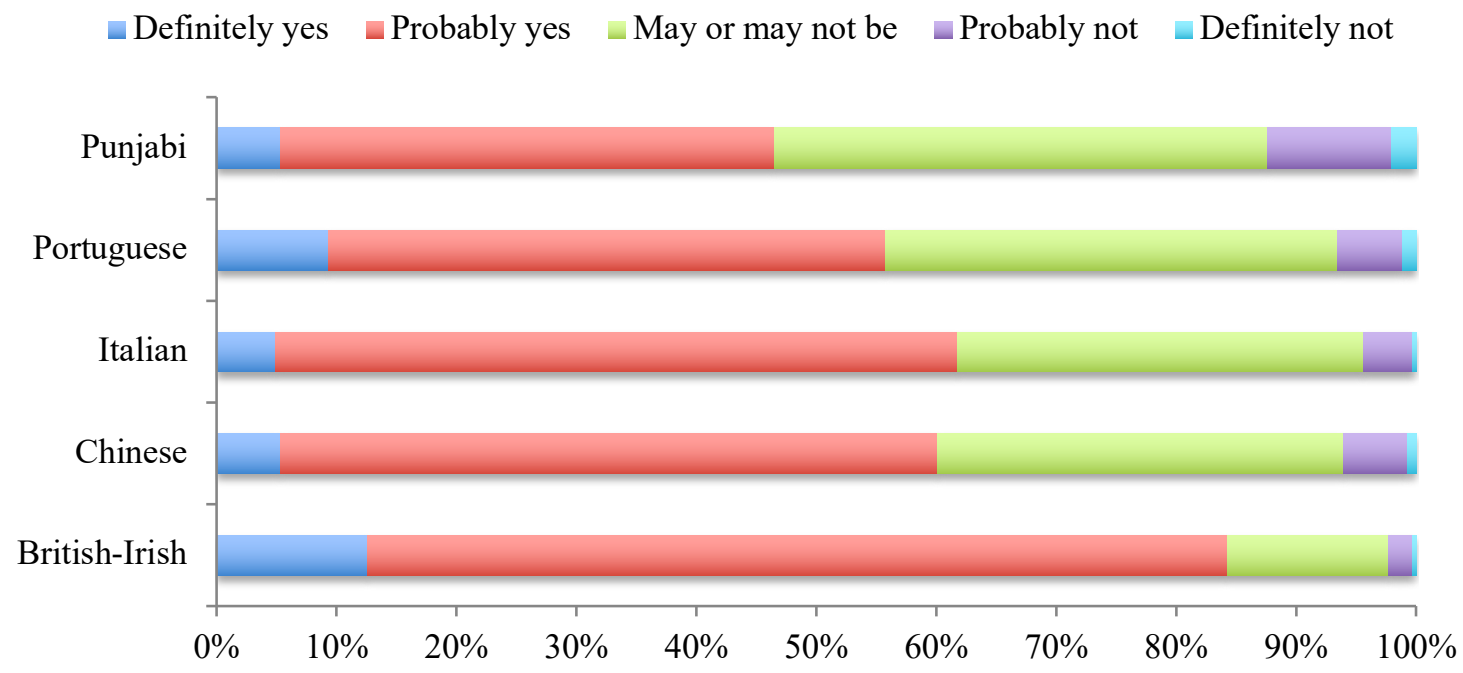

Figure 10. Judgments of whether the Voices are from Toronto, based on judged ethnicity

As we saw for the judgments about speaking English well, the Voice's judged ethnicity has a much larger effect than its actual ethnicity (see Table 6) on judgments of whether a Voice is from Toronto. In fact, the actual ethnicity has no significant effect on these judgments, while the judged ethnicity does. Speakers heard as British are, by far, the most likely to be judged to be from Toronto (in spite of Toronto's fame for being highly "multi-cultural"). Those Voices heard as Chinese and Punjabi are least likely to be judged to be from Toronto. The strongest effect, however, is that the better one is judged to speak English, the more likely they are judged to be from Toronto.

Table 6. Relationship between Judgment of Ethnicity and Judgment of being from Toronto (Ranked by factor weight)

\begin{tabular}{lcclcc}
\hline $\begin{array}{l}\text { Judged ethnicity } \\
(\boldsymbol{p}=\mathbf{1 . 5 e - 1 0 )}\end{array}$ & $\begin{array}{c}\text { Judged from } \\
\text { Toronto }\end{array}$ & Factor weight & $\begin{array}{l}\text { Actual ethnicity } \\
(\mathbf{n . s .}, \boldsymbol{p}=\mathbf{0 . 1 0 1})\end{array}$ & $\begin{array}{c}\text { Judged from } \\
\text { Toronto }\end{array}$ & Factor weight \\
\hline British-Irish & $84 \%$ & 0.78 & Punjabi, High EO & $70 \%$ & 0.59 \\
Italian & $62 \%$ & 0.53 & Chinese, High EO & $55 \%$ & 0.59 \\
\hline Portuguese & $56 \%$ & 0.48 & Italian, Low EO & $71 \%$ & 0.55 \\
Chinese & $59 \%$ & 0.47 & Punjabi, Low EO & $60 \%$ & 0.53 \\
Other & $46 \%$ & 0.37 & Portuguese, Low EO & $66 \%$ & 0.50 \\
Punjabi & $46 \%$ & 0.35 & Chinese, Low EO & $50 \%$ & 0.45 \\
Canadian & $0 \%$ & {$[$ not in model] } & British/Irish & $70 \%$ & 0.44 \\
& & & Italian, High EO & $57 \%$ & 0.43 \\
& & & Portuguese, High EO & $60 \%$ & 0.43 \\
\hline
\end{tabular}

\section{Conclusions}

This pilot study has explored a fruitful methodology - asking participants from a range of ethnic backgrounds to make judgments about a set of Voices from a range of ethnic backgrounds. The on-screen methods, coupled with a face-to-face interaction, ensured a high rate of participation.

We see that people are moderately successful at identifying ethnicity on the basis of a brief clip of a speaker's Voice: overall, one in three judgments were correct. Torontonians are generally better at identifying ethnic groups that have been in Toronto longer (British/Irish, Chinese and Italian). These groups 
are also bigger, so people may have more experience with them. However, we note that while we have a strong representation of Chinese- and British-descent Judges, there are fewer Judges representing other groups.

Judges perform less well at identifying people as being from Toronto: $62 \%$ of the judgments were that the Voice was from Toronto when, in fact, $100 \%$ of the them were second-generation (or later, in the case of the British Voices) Canadians, all born and raised in Toronto. We learned that judgments about speaking well are based more on perceived ethnicity than anything else, including actual ethnicity. The second strongest predictor of whether a Voice is judged to be from Toronto is whether it is judged to speak English well. The actual ethnicity of the Voice and of the Judge are also significant predictors. This set of findings reflects deep-seated attitudes and stereotypes about who speaks well, but it is, to the best of our knowledge, the first empirical evidence of this nature (for Toronto).

These results offer insights into perceptions of and attitudes towards ethnically marked ways of speaking and speakers from different ethnic backgrounds. Future research will examine the linguistic features in the clips to better understand what linguistic cues people are responding to and how these correspond to the inter-group variation that has been identified in production. Thus, this study provides a springboard for future research and to develop educational tools to combat discrimination.

Acknowledgements. We are grateful to the research assistants at York University and the University of Toronto who built the survey and collected the data: Mira Chow, Fatemeh Kavaninzadeh, Latoya Sousa, Pavethira Uthayakumaran, Ashley Villagracia and Christopher Zhu. The work was supported by SSHRC Insight Grant \#GC-2017-Q4-00477 to the first two authors.

\section{References}

Bijvoet, Elin, and Kari Fraurud. 2010. Rinkeby Swedish in the mind of the beholder: Studying listener perceptions of language variation in multilingual Stockholm. In Multilingual urban Scandinavia: new linguistic practices, ed. Pia Quist and Bente Ailin Svendsen, 170-188. Bristol, UK: Multilingual Matters.

Bourhis, Richard, and Anne Maass. 2005. Linguistic prejudice and stereotypes. In Sociolinguistics: An international handbook of the science of language and society, $2^{\text {nd }}$ ed., ed. Ulrich Ammon, Norbert Dittmar, Klaus J. Mattheier, and Peter Trudgill, 1587-1601. Berlin: De Gruyter.

Clopper, Cynthia G., Susannah V. Levi, and David B. Pisoni. 2006. Perceptual similarity of regional dialects of American English. Journal of the Acoustical Society of America 119(1): 566-574.

Eisenchlas, Susana, and Chiharu Tsurutani. 2011. You sound attractive! Perceptions of accented English in a multilingual environment. Australian Review of Applied Linguistics 34(2): 216-236.

Evans, Betsy. 2011. "Seattletonian" to "faux hick": Perceptions of English in Washington State. American Speech 86(4): 383-414.

Harney, Nicholas DeMaria. 1998. Eh, paesan! Being Italian in Toronto. Toronto: University of Toronto Press.

Hoffman, Michol F. 2010. The role of social factors in the Canadian Vowel Shift: Evidence from Toronto. American Speech 85(2): 121-140.

Hoffman, Michol F. 2017. In the front and in the back: The role of ethnicity in back vowel fronting in Toronto English. Paper presented at the annual meeting of the American Dialect Society, Austin, TX.

Hoffman, Michol F., and James A. Walker. 2010. Ethnolects and the city: Ethnic orientation and linguistic variation in Toronto English. Language Variation and Change 22(1): 37-67.

Hoffman Michol F., and James A. Walker. To appear. Portuguese in Toronto: Identity, attitudes and linguistic variation. In Portuguese in Canada: Multidisciplinary contributions to SLA research and practice, ed. Inês Cardoso, Anabela Ratos, and Vander Tavares. Boavista Press Teaching and Learning. 
Hosoda, Megumi, and Eugene Stone-Romero. 2010. The effects of foreign accents on employment-related decisions. Journal of Managerial Psychology 25(2): 113-132.

Johnson, Daniel E. 2009. Getting off the GoldVarb standard: Introducing Rbrul for mixed-effects variable rule analysis. Language and Linguistics Compass 3(1): 359-383.

Kalin, Rudolph, Donald S. Rayko, and N. Love. 1980. The perception and evaluation of job candidates with four different ethnic accents. In Language: Social psychological perspectives, ed. Howard Giles, W. Peter Robinson and Philip M. Smith, 197-202. Oxford: Pergamon.

Kircher, Ruth, and Sue Fox. 2019a. Attitudes towards Multicultural London English: Implications for attitude theory and language planning. Journal of Multilingual and Multicultural Development 40(10): 847-864. DOI: 10.1080/01434632.2019.1577869

Kircher, Ruth and Sue Fox, Sue. 2019b. Multicultural London English and its speakers: A corpus-informed discourse study of standard language ideology and social stereotypes. Journal of Multilingual and Multicultural Development 40(10): 847-864. DOI: 10.1080/01434632.2019.1666856

Levine, Allan. 2014. Toronto: A biography. Toronto: Douglas and McIntyre.

Levon, Erez. 2014. Categories, stereotypes and the linguistic perception of sexuality. Language in Society 43(5): 539-566.

Nagy, Naomi, Joanna Chociej, and Michol Hoffman. 2014. Analyzing ethnic orientation in the quantitative sociolinguistic paradigm. In Language and Communication (35): New perspectives on the concept of ethnolect, ed. Lauren Hall-Lew and Malcah Yaeger-Dror, 9-26.

Nunes, Fernando. 2004. Portuguese-Canadian youth and their academic underachievement: A literature review. Portuguese Studies Review 11(2): 41-87.

Nunes, Fernando. 2008. Striking a balance in Canada's diversity dialogue. Canadian Diversity 12(2): 121125.

Ornstein, Michael. 2006. Ethno-racial groups in Toronto, 1971-2001: A demographic and socio-economic profile. Toronto: York University Institute for Social Research.

Preston, D. R. 2018. Changing research on the changing perceptions of southern U.S. English. American Speech 93(3-4): 471-496.

Purnell, Thomas, William Idsardi, and John Baugh. 1999. Perceptual and phonetic experiments on American English dialect identification. Journal of Language and Social Psychology 18(1): 10-30.

Rocha-Trindade, Maria. 2009. The Portuguese diaspora. In The Portuguese in Canada: Diasporic challenges and adjustment, ed. Carlos Teixeira and Victor Da Rosa, 18-41. Toronto: University of Toronto Press.

Statistics Canada. 2003. Ethnic diversity survey: Portrait of a multicultural society. Ottawa: Ministry of Industry

Statistics Canada. 2016. 2016 Census of Canada: Profile data for Toronto. Ottawa: Statistics Canada.

Teixeira, Carlos, and Robert A. Murdie. 2009. On the move: The Portuguese in Toronto. In The Portuguese in Canada: diasporic challenges and adjustment. ed. Carlos Teixeira and Victor Da Rosa., 191-207. Toronto: University of Toronto Press.

Troper, Harold. 2003. Becoming an immigrant city: A history of immigration into Toronto since the Second World War. In The world in a city, ed. Paul Anisef and C. Michael Lanphier, 19-62. Toronto: University of Toronto Press.

Williams, Angie, Peter Garrett and Nikolas Coupland. 1999. Dialect recognition. In Handbook of perceptual dialectology, ed. Dennis Preston, 345-358. Philadelphia: John Benjamins.

Zucchi, John E. 1988. Italians in Toronto: Development of a national identity, 1875-1935. Montreal/Kingston: McGill-University Press. 


\section{Appendix A: Mixed effects model of Judges' correctness in identifying the Voice's ethnicity ( $N=1,497$, Overall correctness 37\%)}

\begin{tabular}{|c|c|c|c|c|}
\hline Predictor & Logodds & $\mathbf{n}$ & Accuracy & Centered factor weight \\
\hline \multicolumn{5}{|c|}{ Voice's ethnicity $(p=3.42 \mathrm{e}-37)$} \\
\hline Italian, High EO & 0.971 & 175 & $57 \%$ & 0.73 \\
\hline British/Irish & 0.944 & 164 & $56 \%$ & 0.72 \\
\hline Chinese, High EO & 0.808 & 187 & $54 \%$ & 0.69 \\
\hline Punjabi, High EO & 0.425 & 166 & $44 \%$ & 0.61 \\
\hline Chinese, Low EO & 0.12 & 157 & $37 \%$ & 0.53 \\
\hline Punjabi, Low EO & -0.158 & 165 & $31 \%$ & 0.46 \\
\hline Italian, Low EO & -0.643 & 168 & $21 \%$ & 0.35 \\
\hline Portuguese, High EO & -1.078 & 160 & $15 \%$ & 0.25 \\
\hline Portuguese, Low EO & -1.389 & 155 & $12 \%$ & 0.20 \\
\hline \multicolumn{5}{|c|}{ Judge's ethnicity $(p=0.018)$} \\
\hline Portuguese & 0.523 & 153 & $44 \%$ & 0.63 \\
\hline Italian & 0.338 & 96 & $41 \%$ & 0.58 \\
\hline Chinese & 0.177 & 625 & $38 \%$ & 0.54 \\
\hline Jewish & 0.121 & 62 & $34 \%$ & 0.53 \\
\hline Other & 0.085 & 329 & $37 \%$ & 0.52 \\
\hline No response (/) & & 67 & $37 \%$ & \\
\hline British-Irish & -0.369 & 148 & $26 \%$ & 0.41 \\
\hline Punjabi & -0.877 & 17 & $18 \%$ & 0.29 \\
\hline \multicolumn{5}{|c|}{ Judge's age (n.s., $p=0.95$ ) } \\
\hline+1 year & 0.009 & & & \\
\hline \multicolumn{5}{|c|}{ Voice's gender (n.s., $p=0.200$ ) } \\
\hline Female & 0.074 & 701 & $39 \%$ & 0.52 \\
\hline Male & -0.074 & 796 & $35 \%$ & 0.48 \\
\hline \multicolumn{5}{|c|}{ Judge's gender (n.s., $p=0.405$ ) } \\
\hline Non-binary & 0.267 & 70 & $47 \%$ & 0.57 \\
\hline Female & -0.117 & 788 & $37 \%$ & 0.47 \\
\hline Male & -0.149 & 639 & $36 \%$ & 0.46 \\
\hline
\end{tabular}

$N B$ : A second model of the same dependent variable was constructed by eliminating the predictors not significant here and inserting the following predictors: judgment of speaking well, judgment of being from Toronto. Neither was found significant, while the same factors found significant in the above model again emerged as significant, with similar effects. That second model is marginally worse-fitting, according to a comparison of AICc. 


\begin{tabular}{|c|c|c|c|c|}
\hline Predictor & Logodds & $\mathbf{n}$ & Accuracy & Centered factor weight \\
\hline \multicolumn{5}{|l|}{ Judged ethnicity $(p=6.52 \mathrm{e}-20)$} \\
\hline Canadian & 1.650 & 17 & $77 \%$ & 0.84 \\
\hline British-Irish & 1.630 & 351 & $92 \%$ & 0.84 \\
\hline Other & -0.342 & 41 & $68 \%$ & 0.42 \\
\hline Italian & -0.418 & 369 & $65 \%$ & 0.40 \\
\hline Chinese & -0.676 & 286 & $62 \%$ & 0.34 \\
\hline Punjabi & -0.825 & 248 & $49 \%$ & 0.31 \\
\hline Portuguese & -1.018 & 185 & $56 \%$ & 0.27 \\
\hline \multicolumn{5}{|l|}{ Judged as from Toronto $(p=2.88 \mathrm{e}-18)$} \\
\hline Definitely yes & 1.151 & 111 & $87 \%$ & 0.76 \\
\hline Probably yes & 0.718 & 819 & $80 \%$ & 0.67 \\
\hline Definitely not & 0.034 & 12 & $33 \%$ & 0.51 \\
\hline Maybe & -0.743 & 473 & $47 \%$ & 0.32 \\
\hline Probably not & -1.160 & 82 & $29 \%$ & 0.24 \\
\hline \multicolumn{5}{|l|}{ Voice's ethnicity $(p=1.69 \mathrm{e}-08)$} \\
\hline Italian, High EO & 0.623 & 175 & $71 \%$ & 0.65 \\
\hline Chinese, High EO & 0.400 & 187 & $77 \%$ & 0.60 \\
\hline Italian, Low EO & 0.387 & 168 & $77 \%$ & 0.60 \\
\hline Punjabi, Low EO & 0.282 & 165 & $66 \%$ & 0.57 \\
\hline Portuguese, High EO & 0.142 & 160 & $71 \%$ & 0.54 \\
\hline British/Irish & -0.071 & 164 & $77 \%$ & 0.48 \\
\hline Portuguese, Low EO & -0.258 & 155 & $68 \%$ & 0.44 \\
\hline Chinese, Low EO & -0.367 & 157 & $54 \%$ & 0.41 \\
\hline Punjabi, High EO & -1.137 & 166 & $41 \%$ & 0.24 \\
\hline \multicolumn{5}{|l|}{ Judge's ethnicity $(p=0.007)$} \\
\hline British-Irish & 0.931 & 148 & $85 \%$ & 0.72 \\
\hline Punjabi & 0.416 & 17 & $82 \%$ & 0.60 \\
\hline Italian & 0.371 & 96 & $75 \%$ & 0.59 \\
\hline not reported (/) & & 67 & $46 \%$ & \\
\hline Other & -0.310 & 391 & $68 \%$ & 0.42 \\
\hline Chinese & -0.622 & 625 & $66 \%$ & 0.35 \\
\hline Portuguese & -0.786 & 153 & $57 \%$ & 0.31 \\
\hline Judge (std. dev. of random effect) & 1.242 & & & \\
\hline
\end{tabular}




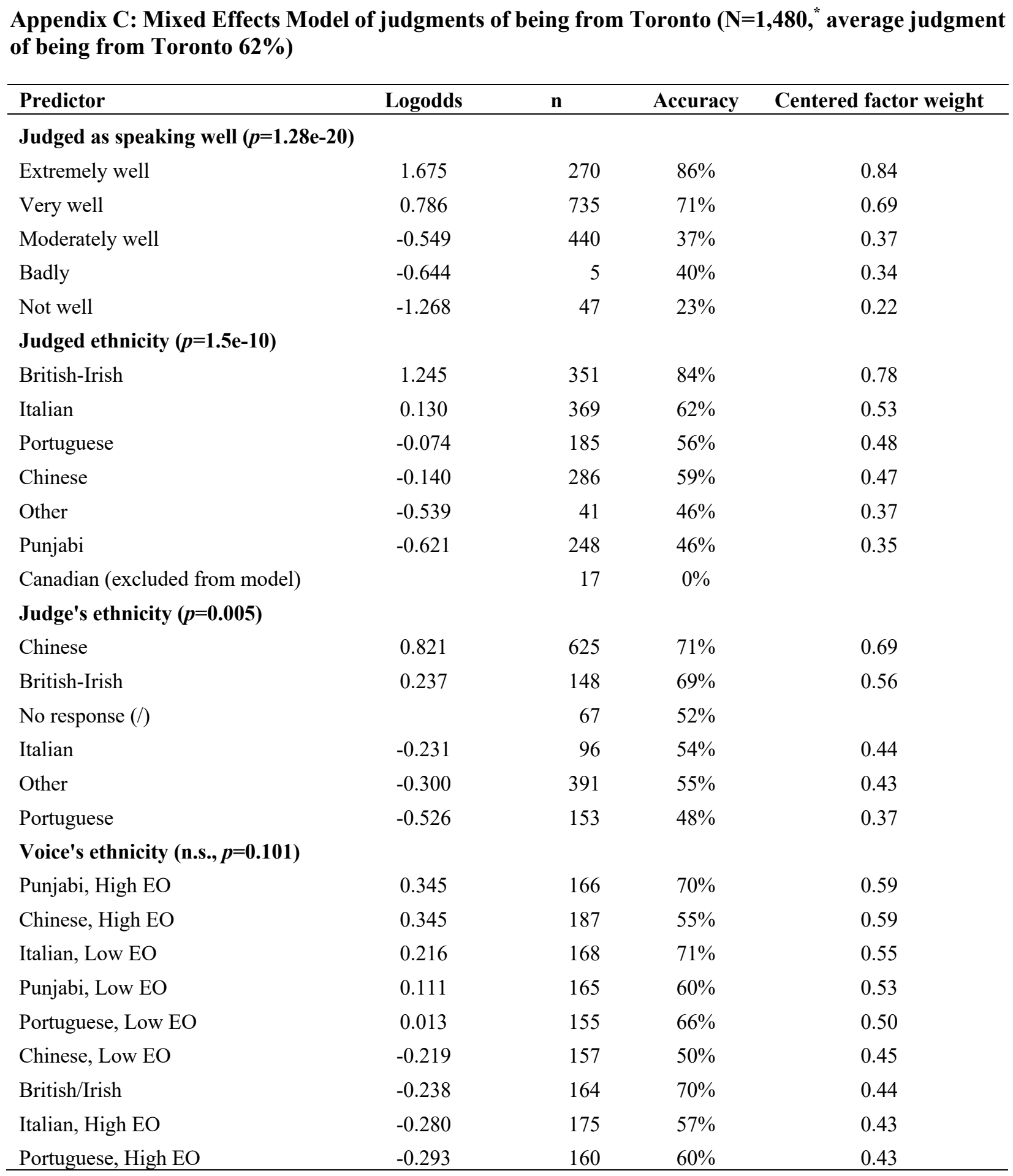

${ }^{*}$ We excluded from this model the 17 responses of the single Punjabi judge. 